\title{
Bat conservation and large dams: spatial changes in habitat use caused by Europe's largest reservoir
}

\author{
Hugo Rebelo*, Ana Rainho \\ Instituto da Conservação da Natureza e da Biodiversidade, Rua de Santa Marta, 55. 1150-249 Lisboa, Portugal
}

\begin{abstract}
Large dams have had a major impact on a number of botanical and faunal groups. Nevertheless, little is known about their effect on bat populations. As part of a multipurpose project, the Alqueva dam was constructed during 2001 in Alentejo (Southern Portugal) and has created the largest reservoir in Europe. Its construction caused major changes in the region, mainly due to the deforestation and submersion of an area of $250 \mathrm{~km}^{2}$. A 2-stage survey was implemented in order to evaluate the impact of these landscape changes on bat populations present in the region, as well as to define minimization and compensation measures. Bat activity was surveyed prior to and after the deforestation and flooding of the area, mainly through the use of ultra-sound detectors. The results show a clear decline in bat activity over the area now submerged; islands within the reservoir seem to be the only remaining foraging areas. Furthermore, bat activity increased in the area surrounding the reservoir. In this area, bats used similar foraging habitat types during both stages of the survey, confirming the importance of riparian habitats as foraging areas. Bat populations of this region were thus affected simultaneously by the disappearance of around $200 \mathrm{~km}$ of riparian habitat, extensive loss of roosts and the creation of a vast homogeneous habitat that is rarely used for foraging. In projects of this dimension, the future of bat communities is clearly dependent on the preservation of roosts and the most important habitats surrounding the reservoir.
\end{abstract}

KEY WORDS: Large dams · Bats · Habitat use $\cdot$ Conservation · Ultra-sound survey

Resale or republication not permitted without written consent of the publisher

\section{INTRODUCTION}

During the 1990s there was a considerable decline in the number of projected big dams. However, with a worldwide increasing energy demand there has been a search for energy sources as an alternative to oil. Some countries are once again turning to giant hydropower, irrigation and water-supply projects (Sullivan 1995, Giles 2006).

In the past, big dams have caused the destruction of forests and wild habitats and, in several situations, caused significant and irreversible damage to species and ecosystems (World Commission on Dams 2000), often with disappointing economic returns compared to investment (Mira da Silva et al. 2001). Despite the general acknowledgement of the negative impacts that such projects have on the environment and biodiversity, little research has focused on this subject (e.g. Park et al. 2003), particularly on the impact of dams on bats (e.g. Cosson et al. 1999b).
The Alqueva project was conceived during the mid 1960 s as a strategic water reservoir with the objective of sustaining the development of irrigated farmland in Alentejo, a dry and underdeveloped region in southern Portugal. However, the project was suspended in the following decades and only restarted in 1992. The Alqueva project currently aims, in addition to its initial goal, to generate hydro-energy and promote tourism in the region. The intent is that the project will be the basis for local development, while reducing the high rate of unemployment in the area. The different stages of the Alqueva dam multi-purpose project dramatically changed the landscape of the area with the conversion of $250 \mathrm{~km}^{2}$ of diverse habitats (e.g. riparian areas, oak woodlands, olive groves) into a single lentic area. In addition to these changes, the creation of large areas for irrigated agriculture are also planned (www.edia.pt).

It is likely that such large changes in the landscape could be limiting for the survival of some bat popula- 
tions (Cosson et al. 1999b), as in the case of the Alqueva dam. Futhermore, all bat roosts and foraging areas located within the reservoir area have been destroyed. This is of special concern for the treedwelling species, since more than 1.3 million trees (mainly oaks) were cut down during the deforestation phase.

Looking at the future of big dams and their impact on wildlife is necessary so that more can be learnt from the success or failure of these projects (World Commission on Dams 2000). Our main objective was thus to investigate how bats respond to vast landscape changes, particularly to flooding, by comparing bat use of an affected area before and after the construction of a big dam.

Prior to this work, no thorough bat survey had ever been done in the Alqueva dam catchment area. Therefore, our main goal was to evaluate bat habitat use before and after the flooding and deforestation phases in order to better assess the consequences of the Alqueva dam for the local bat populations. Hence, we (1) investigated whether there were any differences in bat activity and habitat use in the Alqueva region before and after the flooding, and (2) identified which habitats are of main concern for the conservation of bat populations in the region. In addition, we aimed to define mitigation measures to implement during the project and to discuss possible compensation measures.

\section{MATERIALS AND METHODS}

Study area. The Alqueva dam is located in southern Portugal ( $38^{\circ} 13^{\prime} \mathrm{N}, 7^{\circ} 44^{\prime} \mathrm{W}$; Fig.1) on the river Guadiana. The climate of the region is characterized as thermo-Mediterranean, being a dry region with maximum temperatures in summer frequently over $40^{\circ} \mathrm{C}$ and, in some areas, rainfall as low as $600 \mathrm{~mm} \mathrm{yr}^{-1}$ (Instituto Nacional Meteorologia e Geofísica 1991).

At its maximum capacity, the reservoir of the dam occupies an area of about $250 \mathrm{~km}^{2}$. The study area covered all of Alqueva's catchment area and major subsidiaries, stretching lengthwise approximately $75 \mathrm{~km}$ north from the dam and up to $40 \mathrm{~km}$ in width.

Bat foraging habitats. We carried out fieldwork on the pre-deforestation and flooding phase of the dam (hereafter called 2000) and on the postflooding phase (hereafter called 2003). Due to the resulting landscape changes, 8 habitat types were investi-

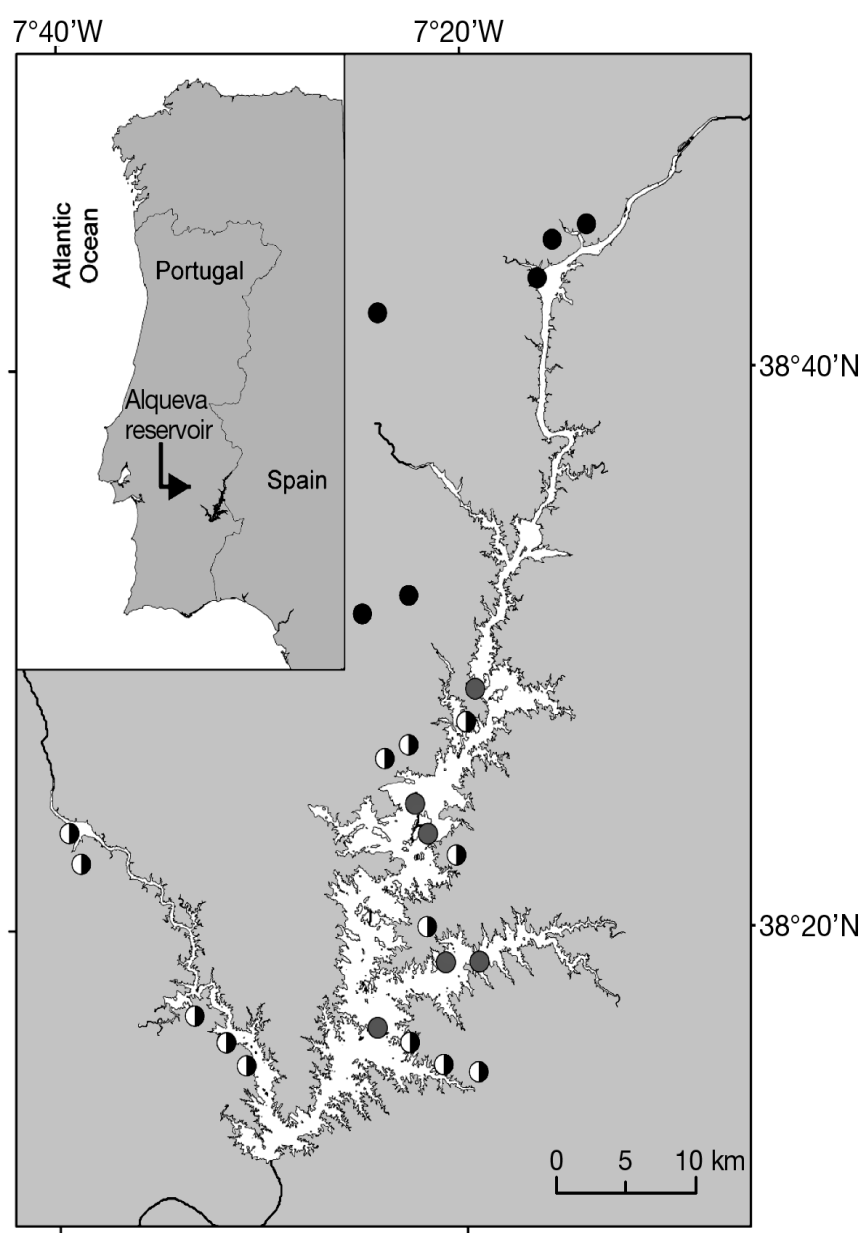

Fig. 1. Location of Alqueva reservoir and sites where transects were examined monthly to determine bat foraging activity. Black dots $(\bullet)$ represent transects in the control region, grey dots $(0)$ in areas directly influenced by the reservoir, and black and white dots ( $)$ in areas contiguous to the reservoir. Due to the scale used, each dot may include more than one transect

Table 1. Habitat types and time spent (h) surveying each one during 2000 and 2003. N: number of sites surveyed for each habitat type; -: no data

\begin{tabular}{|lcccc|}
\hline \multirow{2}{*}{ Habitats } & \multicolumn{2}{c}{2000} & \multicolumn{2}{c|}{2003} \\
& Time (h) & N & Time (h) & N \\
\hline Oak woodland (Oak) & $9: 15$ & 9 & $7: 30$ & 5 \\
Islands (Isl) & - & - & $4: 00$ & 4 \\
Olive groves (Oli) & $4: 30$ & 5 & $3: 45$ & 4 \\
Eucalyptus plantations (Euc) & $2: 30$ & 3 & $3: 00$ & 3 \\
Riparian areas (Rip) & $7: 00$ & 6 & $4: 00$ & 3 \\
Reservoir margins (Mar) & - & - & $3: 45$ & 3 \\
Ponds (Pon) & $3: 15$ & 4 & $3: 30$ & 4 \\
Reservoir (Res) & - & - & $4: 30$ & 4 \\
Irrigated farmland (Irr) & $2: 30$ & 3 & $3: 00$ & 3 \\
Conventional farmland (Con) & $8: 00$ & 9 & $7: 30$ & 5 \\
Deforested areas (Def) & - & - & $2: 30$ & 3 \\
Urban areas (Urb) & $5: 15$ & 4 & $4: 00$ & 4 \\
\end{tabular}


gated in 2000 and 12 in 2003 (Table 1). The area of each habitat was determined by land cover maps using a GIS (Arcview 3.2 ${ }^{\circledR}$, ESRI). Habitat patch size had an average area of 88.84 ha (range $=0.002$ to 1334.846 ha). We planned to make the sampling effort proportional to the availability of each habitat in the area and also to focus on habitats that, despite their low availability, are known to be important to bats (e.g. riparian areas, ponds; see Russo \& Jones 2003, Rainho 2007). Overall, the following habitat types considered were: (1) 'oak woodland' —oak savannah-like woodland mainly of Quercus rotundifolia and/or Q. suber; (2) 'islands' - oak woodland areas within the reservoir that are not submerged at the maximum capacity of the dam; (3) 'olive groves' - orchards of Olea europea; (4) 'Eucalyptus plantations' - production forests of Eucalyptus spp.; (5) 'riparian areas' - margins of rivers and small streams usually with developed riparian vegetation; (6) 'reservoir margins' - margins and banks of the Alqueva reservoir; (7) 'ponds' — small reservoirs for agriculture and/or cattle; (8) 'reservoir' — water surface of the Alqueva dam catchment area; (9) 'irrigated farmland' — conventional farms with irrigation; (10) 'conventional farmland' - farms without irrigation (mainly wheat) and pastures; (11) 'deforested areas' - areas where all vegetation was cut down but not flooded; and (12) 'urban areas' — small villages with street lights. About $22 \%$ of the surveyed sites in 2000 were submerged or deforested (Fig. 1). These sites were surveyed in 2003 under the habitat types deforested areas, reservoir margins, reservoir or islands.

The foraging habitats of bats were surveyed by using transects in each habitat site (Fig. 1); a 15 min walk was needed to cover each transect using an ultrasound detector (D-240 Pettersson Elektronic). This was done at a regular pace, so that around $500 \mathrm{~m}$ were covered. In each transect the number of bat passes and feeding buzzes were counted. Transect surveys started $45 \mathrm{~min}$ after sunset and lasted for $3 \mathrm{~h}$, in accordance with similar studies (e.g. Russo \& Jones 2003, Rainho 2007). Since transect sites were located at least $1 \mathrm{~km}$ from each other, only 5 to 6 transects were covered each night. The order in which the habitats were visited was randomized in order to control for the effect of recording time, given that bat activity could diminish in the latter hours of the sampling period.

Forty-six transects were regularly surveyed (once a month) during 2000, and 36 were surveyed in 2003. These latter transects were in the same location as, or in the vicinity of, the ones surveyed in 2000. Furthermore, 28 new transects were surveyed only once in other sites within the study area (e.g. islands). Data from these new transects was not used for the analysis of the impact of the Alqueva project on bat activity and habitat use.
The reservoir transects were covered on a boat at a low speed, so that the distance travelled on water was similar to that travelled on the land transects surveyed by foot. GPS (Magellan Pro-Mark X) was used for orientation and guidance through a route, and the use of light was avoided. While covering these transects, stops were made to survey islands. Transects were also surveyed in a control region, unaffected by the reservoir, in order to identify possible variations in bat activity between 2000 and 2003 unrelated to the implementation of the Alqueva project. The control region included all the habitats present in the study area except conventional farmland. Whenever weather conditions were adverse for bat activity, such as strong winds or rain, surveys of the transects were cancelled (Siemers \& Schnitzler 2000, Russo \& Jones 2003).

Ultra-sound analysis. All bat calls detected were recorded on a digital recorder (Creative Nomad files saved in WAV format; sampling rate $44.1 \mathrm{kHz}$ and 16 bits/sample) and analysed with sound-analysis software (Avisoft-SAS Lab-Pro v.4.23c) using a 512 pt FFT with Hamming window for spectrogram analysis. Call parameters were measured using crosshair screen cursors; temporal variables were measured from oscillograms, while frequencies were taken from power spectra. Species identification was made using published data on bat calls (Zbinden \& Zingg 1986, Schnitzler et al. 1987. Kalko \& Schnitzler 1989, Jones 1995, Waters \& Jones 1995, Waters et al. 1995, Barlow \& Jones 1997 , Ahlén \& Baagøe 1999, Siemers \& Schnitzler 2000, Russo \& Jones 2002). All calls that could not be clearly identified were classified as unidentified bat passes. The similarity between the echolocation of some species makes it difficult to distinguish them, even after detailed analysis (e.g. Russo \& Jones 2002, Rainho 2007). In Portugal, this is the case for (1) Nyctalus noctula and N. lasiopterus, (2) Pipistrellus pygmaeus and Miniopterus schreibersii, (3) P. pygmaeus and P. pipistrellus, and (4) $P$. pipistrellus and $P$. kuhlii. In the first 2 cases, we assumed that the calls belonged to the most abundant species, N. lasiopterus and P. pygmaeus; N. noctula is extremely rare in Portugal, probably only present during winter (Rainho et al. 1998), while $M$. schreibersii can be relatively abundant but only in the vicinity of important underground roosts. In relation to the latter 2 cases, we found no conclusive evidence that $P$. pipistrellus, so far only recorded in northern Portugal, is present in the region $(\mathrm{H}$. Rebelo \& A. Rainho unpubl. data). This species was thus not considered for analysis.

To evaluate the reliability of each species' identification, the first author's ability to identify the species through their echolocation calls was tested. For that, we used 74 call sequences of several species from individuals of known identity recorded either at roost 
entrance or after hand release. The results are presented in a classification matrix (Appendix 1).

Data analysis. Preliminary data analysis (whiskeredboxes, Kolmogorov-Smirnov test, Levene test) showed that data for 2000 and 2003 were not homogeneous and that they had neither normal distribution nor similar variances in the different groups, even after data transformation (square root, $\log _{e}, \log _{x+1}$ ). Therefore, in order to test if bats changed their habitat preferences between 2000 and 2003 (considering only the 8 habitat classes that existed both before and after the flooding) a Kruskal-Wallis test (Siegel \& Castellan 1988) was used. Likewise, to test for differences on bat habitat use in (1) directly affected areas (flooded or deforested) and in (2) regions surrounding flooded and deforested areas, a Mann-Whitney $U$-test and a 2-tailed Wilcoxon matched-pairs signed-ranks test (Zar 1984, Siegel \& Castellan 1988) were used, respectively. Data between 2000 and 2003 from the control region was also tested using the Mann-Whitney $U$-test.

To determine the relationship between bat passes and feeding buzzes the Spearman rank correlation coefficient was used. Whenever needed, the average and standard deviation of bat passes per transect are presented. All statistical analysis was performed in SPSS 14.0 for Windows (SPSS).

\section{RESULTS}

During 2000, 494 bat passes were counted in a total of $45 \mathrm{~h}$ and $15 \mathrm{~min}$ of transect surveys. In 2003, transects were covered for a total of $50 \mathrm{~h}$ and $30 \mathrm{~min}$ and 946 bat passes counted. Due to a high correlation value between bat passes and feeding buzzes both in 2000 (Spearman's rank correlation, $\mathrm{r}_{\mathrm{S}}=0.80 ; \mathrm{p}=$ $0.0030)$ and in $2003\left(r_{S}=0.86 ; p=0.0003\right)$, only bat passes were used to analyse the bat activity and habitat use.
In spite of the confirmed presence of 14 bat species in the area (resulting from roost inspections, mistnetting and acoustic surveys), only 10 bat species were identified by their echolocation characteristics. Overall, the most abundant and generalist species recorded belonged to the Pipistrellus genera (Table 2). Besides these, only Eptesicus serotinus and Nyctalus lasiopterus were frequently detected.

\section{Differences in bat activity between 2000 and 2003 (control area)}

As was the case in other studies (e.g. Cosson et al. 1999a), several habitats were surveyed in an area that was not affected by the dam scheme (see Fig. 1) in order to identify differences in bat use unrelated to the deforestation and flooding of the Alqueva reservoir. Results show no differences in bat activity in the control area between 2000 and $2003\left(U=168.5 ; N_{2000}=22\right.$; $N_{2003}=19 ; \mathrm{p}=0.573$ ); therefore, we assume that any detected changes in the following habitat use analysis are linked to the landscape changes related to the Alqueva project.

\section{Differences in habitat use between 2000 and 2003}

Changes in habitat preferences. Data obtained for each habitat type was compared to determine if bat use of the available habitats changed from 2000 to 2003 (Fig. 2). Results showed significant differences (Kruskal-Wallis, $H=20.58$; df $=2$; p < 0.0001) in bat habitat use. Furthermore, as shown in Fig. 2, the most prominent result is the overall increase in the number of bat passes recorded in 2003 in almost all habitat types (exception made for Eucalyptus plantations). In the case of the habitats riparian areas, ponds, oak woodland, urban areas and olive groves that increase

Table 2. Total number of bat species passes recorded in each habitat. See Table 1 for habitat abbreviations. Asterisks: species associated with tree roosts

\begin{tabular}{|c|c|c|c|c|c|c|c|c|c|c|c|c|c|}
\hline Species & Oak & Isl & Oli & Euc & Rip & Mar & Pon & Res & Irr & Con & Def & Urb & $\begin{array}{l}\% \text { of } \\
\text { total }\end{array}$ \\
\hline Rhinolophus ferrumequinum & 0 & 0 & 0 & 0 & 1 & 0 & 0 & 0 & 0 & 0 & 0 & 0 & 0.1 \\
\hline Myotis myotis & 1 & 0 & 0 & 0 & 0 & 1 & 0 & 0 & 0 & 0 & 0 & 0 & 0.1 \\
\hline Myotis daubentonii & 0 & 0 & 0 & 0 & 0 & 0 & 7 & 0 & 0 & 0 & 0 & 0 & 0.5 \\
\hline Myotis nattereri & 0 & 0 & 0 & 0 & 1 & 0 & 0 & 0 & 0 & 0 & 0 & 0 & 0.1 \\
\hline Nyctalus leisleri* & 0 & 0 & 0 & 0 & 1 & 0 & 0 & 0 & 0 & 0 & 0 & 0 & 0.1 \\
\hline Nyctalus lasiopterus * & 0 & 2 & 2 & 1 & 15 & 0 & 0 & 1 & 0 & 1 & 0 & 11 & 2.4 \\
\hline Eptesicus serotinus* & 13 & 19 & 1 & 1 & 58 & 12 & 3 & 0 & 0 & 2 & 0 & 5 & 8.4 \\
\hline Pipistrellus kuhlii* & 64 & 19 & 23 & 17 & 95 & 30 & 59 & 2 & 3 & 5 & 0 & 98 & 30.7 \\
\hline Pipistrellus pygmaeus & 67 & 29 & 10 & 1 & 482 & 77 & 39 & 1 & 3 & 11 & 1 & 48 & 56.9 \\
\hline Tadarida teniotis & 0 & 0 & 1 & 0 & 8 & 0 & 0 & 0 & 0 & 0 & 0 & 0 & 0.7 \\
\hline
\end{tabular}




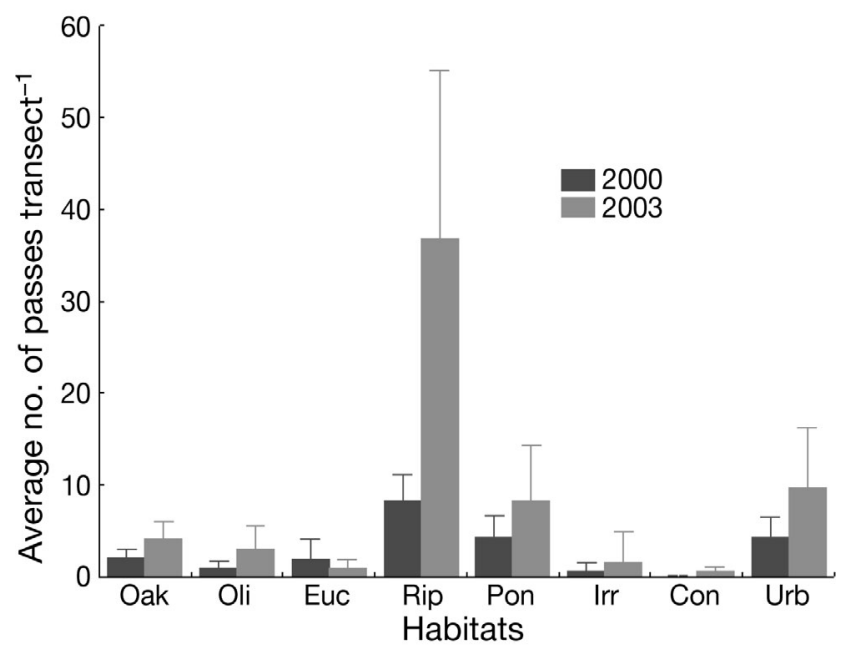

Fig. 2. Average number of bat passes per transect in the years 2000 and 2003. Vertical lines show the $95 \%$ confidence limits. See Table 1 for habitat abbreviations

was more than $200 \%$. Overall, greater bat activity was registered in riparian areas, ponds and urban areas for both 2000 and 2003.

Changes in areas directly influenced by the reservoir. In order to evaluate if bat use changed in areas directly affected by the reservoir, we tested bat activity recorded during 2000 and 2003 where the habitat changed from the original habitat (2000) to reservoir, deforested areas or islands (previously oak woodland) (Fig. 3). Taking these sites together, no significant differences in relation to the bat activity were found $(U=$ 947.5; $N_{2000}=44 ; N_{2003}=46 ; \mathrm{p}=0.59$ ). However, an indepth analysis per habitat showed that islands displayed a highly significant increase in bat activity $(U=$

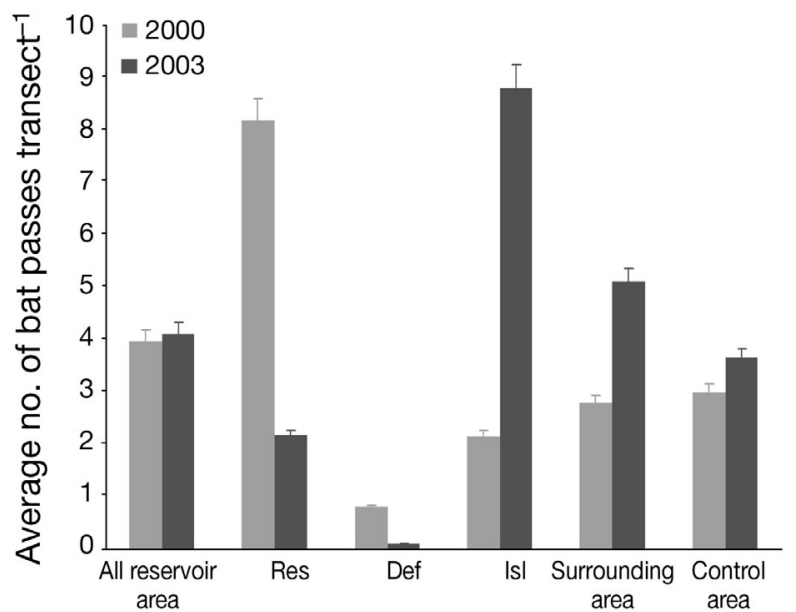

Fig. 3. Comparison of bat activity between 2000 and 2003 in habitats located in the current reservoir area. 2000 data show original habitat for Res, Def and Isl. Vertical lines show the $95 \%$ confidence limits. See Table 1 for habitat abbreviations
59.5; $\left.N_{2000}=16 ; N_{2003}=21 ; \mathrm{p}=0.001\right)$ in relation to the previously existing oak woodland (mean bat passes/transect: islands $8.8 \pm 7.7$; oak woodland $2.1 \pm$ 2.5). On the contrary, reservoir and deforested areas showed a clear decline in bat activity when compared to the original habitats (deforested: $U=29.0 ; N_{2000}=10$; $N_{2003}=10 ; \mathrm{p}=0.049$; reservoir: $U=62.0 ; N_{2000}=18$; $N_{2003}=16 ; \mathrm{p}=0.004$ ).

Changes in the areas surrounding the Alqueva reservoir. Here we compare the results from transects that suffered no major changes in their landscape during the course of this study but that were located in areas very near landscape altered by flooding and/or deforestation. Significant differences were found (Fig. 3) regarding bat activity between 2000 and 2003 (Wilcoxon matched-pairs signed-ranks test; $W=$ $-209.0 ; \mathrm{p}<0.05$; $\mathrm{n}=125$ ) with bats being more frequently detected in 2003 (mean bat passes/transect: $5.1 \pm 8.7)$ than in $2000(2.8 \pm 4.3)$. In both years, riparian areas and ponds were the most used bat habitats.

\section{Bat foraging habitats in the post-flooding phase (2003)}

During 2003 the mean bat passes per transect was $7.1 \pm 14.9$, and significant differences were found in habitat use by bats $(H=59.7$; $d f=11$; $p<0.0001)$. The highest species diversity and number of bat passes was found in riparian areas (9 species, including 5 threatened species and around $41 \%$ of the total number of bat passes), thus making it the most important habitat for bats in the present landscape (Fig. 2 \& 4). Also, the habitats urban areas, islands, reservoir margins and ponds are of some relevance, i.e. number of bat passes

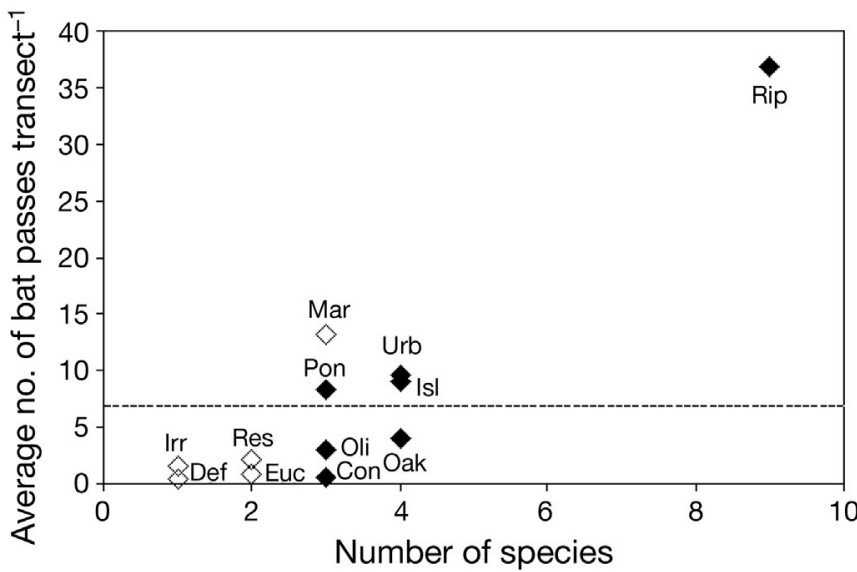

Fig. 4. Habitat importance considering mean bat pass number and species diversity. Presence $(\diamond)$ or absence $(\diamond)$ of threatened species in a habitat; horizontal dashed line shows total average of bat passes. See Table 1 for habitat abbreviations 
above the mean and considerable species diversity. On the other hand, habitats like reservoir, Eucalyptus plantations, irrigated farmland and deforested areas have shown little importance for bats, as there are low levels of bat activity and diversity there.

\section{DISCUSSION}

\section{Differences in bat activity and habitat use between 2000 and 2003}

In general, our results show that bat activity has increased between the surveys carried out in 2000 and 2003. Although the preferred foraging habitats types kept the same activity ranking between those 2 years, the spatial pattern of habitat use shifted, since the flooding apparently forced bats to move to surrounding areas of the Alqueva reservoir. The destruction of roosts (especially for tree-dwelling species) and foraging areas could have led to a concentration of bats as close as possible to their former roosts and foraging areas, hence the detected high levels of bat activity in the areas surrounding the Alqueva reservoir. It is uncertain whether this is a temporary situation resulting from a very recent change in the landscape and whether bats will be able to establish permanent and stable colonies in these new territories.

The detected increase in overall bat activity was mainly caused by individuals of the genera Pipistrellus. Nevertheless, there was also a considerable increase in the number of bat passes of tree-dwelling species, especially in the surrounding area of Alqueva reservoir and its islands. Moreover, it was not possible to assess the impact of the dam scheme on the more threatened bat species, which are of more concern, due to very limited data collected on these species throughout the project. Generalist species seem to be less sensitive to habitat fragmentation than others (Cosson et al. 1999b). What is clear is that changing $250 \mathrm{~km}^{2}$ of diverse landscape into an area constituted mainly by reservoir and deforested areas (the island area within is minimal) represents a loss of foraging habitats and roosts for all bat species present. It was not possible to determine how damaging this event was to the future of these species in the region, but the loss of these roosts is expected to have had a considerable impact.

\section{Bat foraging habitats in the post-flooding phase} (2003)

Islands seem to be of special importance for bat conservation in this area, as they are the only areas within the reservoir that have a considerable number and diversity of foraging bats. The distance between the islands and the mainland does not seem to be important for bat use since this distance $(0.1$ to $1 \mathrm{~km})$ is less than what several bat species normally fly between their roosts and their feeding areas (e.g. Arlettaz 1996, Robinson \& Stebbings 1997, Marques et al. 2004). Bats may avoid open areas because they are more vulnerable to predators there or simply because these areas have a lower abundance and diversity of prey. Furthermore, this avoidance may also be related to the loss of recognisable features for flight paths (Verboom et al. 1999). In consequence, both the reservoir and the deforested areas were rarely used by bats.

Clearly, riparian areas are the most important habitat for bats in this study area, showing greater diversity of species and a higher number of bat passes than in any other habitat type. Several works have shown that this habitat is of extreme importance for bat conservation in Europe (e.g. Vaughan et al. 1997, Grindal et al. 1999, Russo \& Jones 2003) and, more specifically, for the south of Portugal, where the climate is very dry (Rainho 2007). This type of habitat supports a greater diversity and density of insects than any other (Barclay 1991); this availability of prey also seems to support a high richness of foraging bats (Lloyd et al. 2006) and seems to be essential to the conservation of threatened species such as Rhinolophus ferrumequinum and Myotis nattereri (Jones 1990, Siemers \& Schnitzler 2000). Although the creation of small reservoirs (e.g. ponds) may create riparian habitats, this is frequently not the case in large dam schemes such as the present one. The water level variation in the Alqueva reservoir results in a strip of barren land at its margins; during summer, this may reach a width of $1 \mathrm{~km}$ in some of the flattest areas, which is unsuitable for the development of vegetation.

On the other hand, the habitats urban areas, islands, reservoir margins with vegetation and small ponds are of interest due to the considerable number of bat passes and species diversity there. The co-existence of these habitats, together with riparian areas, seems to be a key factor for the maintenance of bat diversity in the region.

\section{Conservation implications}

It is clear that the preservation of areas with higher bat activity and diversity surrounding reservoirs is a priority for the maintenance of bat populations. Furthermore, the remaining trees in the affected area constitute the only available roosts for tree-dwelling bats. Therefore, measures should be taken to preserve vegetated areas, both on the islands and on the reservoir margins. 
The impact of projects of this magnitude extends beyond the reservoir itself, as bat populations are forced to move to the surrounding areas. Moreover, usually large portions of these surrounding areas are scheduled to undergo major landscape changes, either for agricultural purposes, tourism or other types of developments inherent in this kind of project (e.g. it is planned that the Alqueva project will support $1100 \mathrm{~km}^{2}$ of irrigated agriculture, while the reservoir itself occupies another $250 \mathrm{~km}^{2}$ ). The conversion of vast areas to intensive farmland may further contribute to the decline of bat populations, as it causes the homogenization of the habitat. A probable increase in the use of pesticides will also result in a reduction in the abundance and diversity of prey (Limpens \& Kapteyn 1991, Wickramasinghe et al. 2003), as well as directly poisoning the bats (Geluso et al. 1976, Allinson et al. 2006). To minimize the negative impact this may cause, the management of these areas should consider a non fragmentation of the natural habitat (Walsh \& Harris 1996), maintaining a connectivity between the oak woodland and riparian areas through vegetation corridors, and maximizing landscape complexity by encouraging the planting of crops appropriate for each soil type, which will result in a limited use of pesticides (Hutson et al. 2001). Associated with these measures, a monitoring program should be developed to evaluate what impact future irrigated farmlands will have on the bat populations, as illustrated by a comprehensive study made in a South American reservoir, which showed that $3 \mathrm{yr}$ after the flooding the diversity and abundance of frugivorous bats diminished in the affected area (Cosson et al. 1999a).

Acknowledgements. The authors acknowledge the special support of Carlos Carrapato, Mafalda Frade, José Perdigão, Alexandra Freitas, João Almeida e Catarina Azinheira. We thank the numerous people and institutions that made this work possible. Jon Flanders, Sofia Lourenço and João Tiago Marques kindly reviewed a draft of this work. We also thank 2 anonymous reviewers for their useful comments. The nocturnal boat transects were made possible with a permit from DRAOT-Beja and bat capture and handling with a permit from ICNB. The boat 'Sarumugo' was kindly provided by Parque Natural do Vale do Guadiana. This research was supported by EDIA, ICNB and the European Regional Development Fund.

\section{LITERATURE CITED}

Ahlén I, Baagøe HJ (1999) Use of ultrasound detectors for bat studies in Europe: experiences from field identification, surveys and monitoring. Acta Chiropt 1:137-150

Allinson G, Mispagel C, Kajiwara N, Anan Y and others (2006) Organochlorine and trace metal residues in adult southern bent-wing bat (Miniopterus schreibersh bassanii) in southeastern Australia. Chemosphere 64: $1464-1471$
Arlettaz R (1996) Feeding behaviour and foraging strategy of free-living mouse-eared bats, Myotis myotis and Myotis blythii. Anim Behav 51:1-11

Barclay RMR (1991) Population structure of temperate zone insectivorous bats in relation to foraging behaviour and energy demand. J Anim Ecol 60:165-178

Barlow KE, Jones G (1997) Differences in songflight calls and social calls between two phonic types of the vespertilionid bat Pipistrellus pipistrellus. J Zool (Lond) 241:315-324

Cosson JF, Pons JM, Masson M (1999a) Effects of forest fragmentation on frugivorous and nectarivorous bats in French Guiana. J Trop Ecol 15:515-534

Cosson JF, Ringuet S, Claessens O, de Massary JC and others (1999b) Ecological changes in recent land-bridge islands in French Guiana, with emphasis on vertebrate communities. Biol Conserv 91:213-222

Geluso KN, Altenbach JS, Wlson DE (1976) Bat mortality: pesticide poisoning and migratory stress. Science 194:184-186

Giles J (2006) Tide of censure for African dams. Nature 440:393-394

Grindal SD, Morissette JL, Brigham RM (1999) Concentration of bat activity in riparian habitats over an elevational gradient. Can J Zool 77:972-977

Hutson AM, Mickleburgh SP, Racey PA (2001) Microchiropteran bats: global status survey and conservation action plan. IUCN, Gland

Instituto Nacional de Meteorologia e Geofísica (1991) O Clima de Portugal. Fascículo XLIX, Vol 4, $4^{\text {a }}$ Região, Alentejo e Algarve, Normais Climatológicas correspondentes a 1951-1980. INMG, Lisbon

Jones G (1990) Prey selection by the greater horseshoe bat (Rhinolophus ferrumequinum): optimal foraging by echolocation? J Anim Ecol 59:587-602

Jones G (1995) Flight performance, echolocation and foraging behaviour in noctule bats Nyctalus noctula. J Zool (Lond) 237:303-312

Kalko E, Schnitzler HU (1989) The echolocation and hunting behaviour of Daubenton's bat, Myotis daubentonii. Behav Ecol Sociobiol 24:225-238

Limpens HJGA, Kapteyn K (1991) Bats, their behaviour and linear landscape elements. Myotis 29:39-48

> Lloyd A, Law B, Goldingay R (2006) Bat activity on riparian zones and upper slopes in Australian timber production forests and the effectiveness of riparian buffers. Biol Conserv 129:207-220

Marques JT, Rainho A, Carapuço M, Oliveira P, Palmeirim JM (2004) Foraging behaviour and habitat use by the European free-tailed bat Tadarida teniotis. Acta Chiropt 6:99-110

Mira da Silva L, Park JR, Keatinge JDH, Pinto PA (2001) I. A decision support system to improve planning and management of large irrigation schemes. Agric Water Manag 51:187-201

Park Y, Chang J, Lek S, Cao W, Brosse S (2003) Conservation strategies for the endemic fish species threatened by the Three Gorges dam. Conserv Biol 17:1748-1758

$>$ Rainho A (2007) Summer foraging habitats of bats in a Mediterranean region of the Iberian Peninsula. Acta Chiropt 9:171-181

Rainho A, Rodrigues L, Bicho S, Franco C, Palmeirim JM (1998) Morcegos das Áreas Protegidas Portuguesas (I). ICN, Lisbon

Robinson MF, Stebbings RE (1997) Home range and habitat use by the serotine bat, Eptesicus serotinus, in England. J Zool (Lond) 243:117-136

$>$ Russo D, Jones G (2002) Identification of twenty-two bat species (Mammalia: Chiroptera) from Italy by analysis of 
time-expanded recordings of echolocation calls. J Zool (Lond) 258:91-103

Russo D, Jones G (2003) Use of foraging habitats by bats in a Mediterranean area determined by acoustic surveys: conservation implications. Ecography 26:197-209

Schnitzler HU, Kalko E, Miller LA, Surlykke A (1987) The echolocation and hunting behaviour of the bat, Pipistrellus kuhli. J Comp Physiol A 161:267-274

Siegel S, Castellan NJ Jr (1988) Nonparametric statistics for the behavioral sciences, 2nd edn. McGraw-Hill International Editions, New York

Siemers BM, Schnitzler HU (2000) Natterer's bat (Myotis nattereri Kuhl, 1818) hawks for prey close to vegetation using echolocation signals of very broad bandwith. Behav Ecol Sociobiol 47:400-412

Sullivan LR (1995) The 3 Gorges project - Damned if they do. Curr Hist 94:266-269

Vaughan N, Jones G, Harris S (1997) Identification of British bat species by multivariate analysis of echolocation call parameters. Bioacoustics 7:169-207

Verboom B, Boonman AM, Limpens HJGA (1999) Acoustic perception of landscape elements by the pond bat (Myotis dasycneme). J Zool (Lond) 248:59-66

- Walsh AL, Harris S (1996) Factors determining the abundance of vespertilionid bats in Britain: geographical, land class and local habitat relationships. J Appl Ecol 33:519-529

- Waters DA, Jones G (1995) Echolocation call structure and intensity in five species of insectivorous bats. J Exp Biol 198:475-489

Waters DA, Rydell J, Jones G (1995) Echolocation call design limits on prey size: a case study using the aerial-hawking bat Nyctalus leisleri. Behav Ecol Sociobiol 37:321-328

> Wickramasinghe LP, Harris S, Jones G, Vaughan N (2003) Bat activity and species richness on organic conventional farms: impact of agricultural intensifiication. J Appl Ecol 40:984-993

World Comission on Dams (2000) Dams and development: a new framework for decision making. Earthscan Publications, London

Zar JH (1984) Biostatiscal analysis. Prentice Hall International, Engelwood Cliffs, NJ

Zbinden K, Zingg PE (1986) Search and hunting signals of echolocating European free-tailed bats, Tadarida teniotis, in southern Switzerland. Mammalia 50:9-25

Appendix 1. Classification table summarising the results of the identification of 74 echolocation sequences of 16 bat species. Values in the diagonal represent the number of sequences correctly classified. Notice that, as discussed in the text, Miniopterus schreibersii was not considered in the identifications and thus is classified as Pipistrellus pygmaeus. Overall, the results show good performance of the identification procedure. R.ferr: Rhinolophus ferrumequinum; R.hipp.: Rhinolophus hipposideros; M.myot: Myotis myotis; M.emar: Myotis emarginatus; M.natt; Myotis nattereri; M.daub: Myotis daubentonii; M.bech: Myotis bechsteinii; N.leis: Nyctalus leisleri; N.noct: Nyctalus noctula; Plec.sp.: Plecotus sp.; E.sero: Eptesicus serotinus; P.pipi: Pipistrellus pipistrellus; P.pygm: Pipistrellus pygmaeus; P.kuhl: Pipistrellus kuhlii; M.schr: Miniopterus schreibersii; T.teni: Tadarida teniotis; Myot.sp.: Myotis sp.; Pipi.sp.: Pipistrellus sp.; Rin.sp.: Rhinolophus sp.; the n.i. column aggregates non-identified sequences

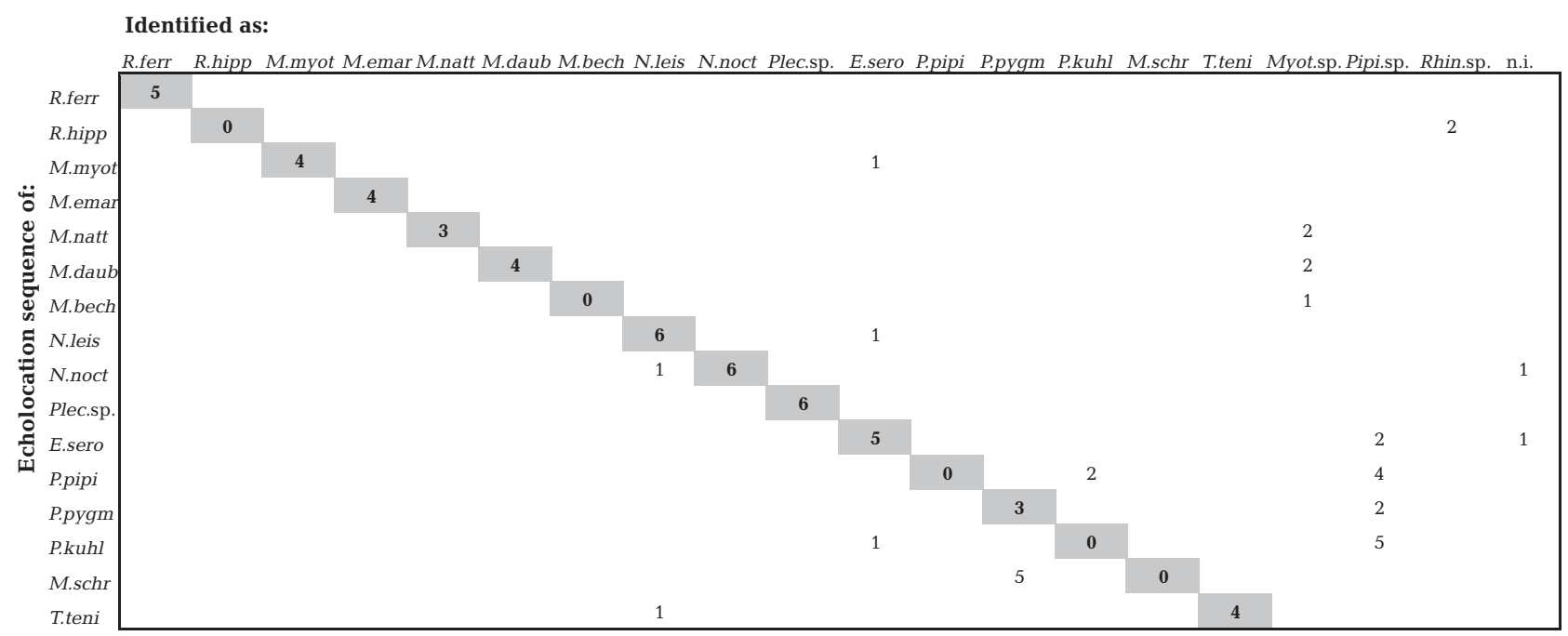

Editorial responsibility: Stephen Rossiter, London, UK
Submitted: January 19, 2008; Accepted: April 24, 2008

Proofs received from author(s): June 17, 2008 